\title{
Homologies between Bauhinia forficata Link subsp. pruinosa and pancreatic beta-cell specific transcriptional activator: a starting point for drug design new in diabetes?
}

\author{
Luis Jesuino de Oliveira Andrade*, Gabriela Correia Matos de Oliveira, Paulo Roberto Santana de Melo, \\ Hudson Sá Sodré, Carlos Alberto Menezes, Alcina Maria Vinhaes Bittencourt
}

From 20th Brazilian Diabetes Society Congress

Porto Alegre, Brazil. 11-18 November 2015

\section{Background}

Diabetes mellitus (DM) is a chronic disease with an everincreasing incidence in world and has become the object of scientific research into the search for novel therapeutic alternatives. Bauhinia forficata Link, known locally as cow foot, has been traditionally used as tea in folk medicine of Brazil for treatment of DM.

\section{Objective}

The purpose of this study is to explore the possible homology between the AA sequences of ribulose 1,5biphosphate carboxylase large subunit, partial (chloroplast) [Bauhinia forficata subsp. pruinosa] and pancreatic beta-cell specific transcriptional activator [Homo sapiens], using databanks of proteins of National Center for Biotechnology Information (NCBI).

\section{Materials and methods}

Were performed the comparison between the AA sequence of the GenBank: CAA94019.1-ribulose 1,5biphosphate carboxylase large subunit, partial (chloroplast) [Bauhinia forficata subsp. pruinosa] and GenBank: BAC20389.1-pancreatic beta-cell specific transcriptional activator [Homo sapiens], available in the database of NCBI with the Basic Local Alignment Search Tool (BLASTp) software.

\section{Results}

The homology between the ribulose 1,5-biphosphate carboxylase large subunit, partial (chloroplast) [Bauhinia forficata subsp. pruinosa] and the pancreatic beta-cell specific transcriptional activator [Homo sapiens] ranged from $48.0 \%$ to $63.0 \%$ (Fig.1).

\section{Conclusion}

Bioinformatics data, suggest a possible pathogenic link between ribulose 1,5-biphosphate carboxylase large subunit, partial (chloroplast) [Bauhinia forficata subsp. pruinosa] and pancreatic beta-cell specific transcriptional activator [Homo sapiens], and studies on this plant are important to the safe, effective development of pharmaceutical products for the treatment of diabetes.

Published: 11 November 2015

doi:10.1186/1758-5996-7-S1-A245

Cite this article as: de Oliveira Andrade et al:: Homologies between

Bauhinia forficata Link subsp. pruinosa and pancreatic beta-cell specific transcriptional activator: a starting point for drug design new in diabetes? Diabetology \& Metabolic Syndrome 2015 7(Suppl 1):A245.

\footnotetext{
* Correspondence: luis_jesuino@yahoo.com.br

Universidade Estadual de Santa Cruz - Bahia, Itabuna, Brazil
} 


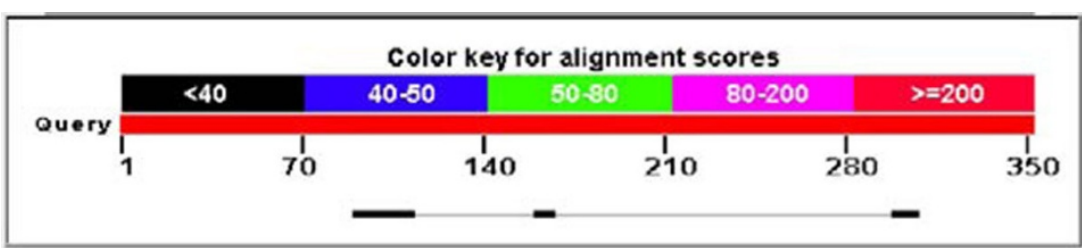

ribulose 1,5-biphosphate carboxylase large subunit [Bauhinia forficata subsp. pruinosa] Sequence ID: embICAA94019.11 Length: 455 Number of Matches: 3

Range 1: 179 to 186 GenPept Graphics

Score Expect Method $\quad$ Identities Positives Gaps

15.4 bits(28) $3.1 \quad$ Compositional matrix adjust. $\quad 5 / 8(63 \%) \quad 5 / 8(62 \%) \quad 0 / 8(0 \%)$

Query 161 ARYEAFRG 168

Sbjet 179 AVYECTRG 186

Range 2: 323 to 332 GenPeot Graohics

Score Expect Method Identities Dositives Gaps

14.6 bits(26) $5.2 \quad$ Compositional matrix adjust. $\quad 5 / 10(50 \%) \quad 8 / 10(80 \%) \quad 0 / 10(0 \%)$

Query 299 VGRLAKERDL 308

Sbjet 323 VGKLEGEREI 332

Range 3: 395 to 416 GenPept Graphies

Score Expect Method Identities Positives Gaps

15.8 bits(29) 2.3 Compositional matrix adjust. $12 / 25(48 \%) \quad 14 / 25(56 \%) 4 / 25(16 \%)$

Query 91 GGMPGPPSGG-PGNVGGTSGKPNIE 114

Sbjet 395 GG G P G PGAV + + ALE

Figure 1 Homologies between bauhinia forficata link subsp., pruinosa and pancreatic beta-cell specific transcriptional activator. 